\title{
Training Future Scientists - Enhancing Research Capabilities in Developing Nations
}

\author{
Emmanuel Coronel, ${ }^{1 *}$ Lorenzo Anez-Bustillos, ${ }^{2 *}$ Felipe Fregni ${ }^{3}$
}

$P P C R$ - Clinical Research $\mathrm{Fe}$ llow Practice website:

www.clinicalresearchlearning.org
"Give a man a fish and you will feed him for a day. Teach a man how to fish and you will feed him for a lifetime"

\section{Chinese proverb}

Not surprisingly, the main bulk of scientific contributions currently present in the literature come from research performed in developed nations. The lack of government funding, unclear health research priorities, and problems retaining scientific researchers, are among the reasons why this disparity has historically held true.' These arguments lead underdeveloped countries to blindly accept the erroneous fact that patient care and scientific research do not belong in the same equation. Medical research has not been a health reform priority in most of these nations, and thus has been traditionally underfunded. The allocation of government funds to this field and the priority it is given reflects its unequal development among many regions of the world.' Consequently, resources destined to train scientists and improve the research infrastructure and equipment are nowhere near the top of the priority list.

In the past few years, regional and global changes have been developed with the purpose of enhancing health research opportunities in non-traditional countries. There seems to be a growing consensus that many answers to common health problems can be provided by performing research. In light of this, the idea of creating knowledge-based economies in many emerging nations (i.e. Brazil, India, Russia, and China) has made research development one of its critical components. Similarly, the globalization phenomenon has motivated these nations to understand the role of research as a potential driving force for their economic growth, as has happened with many other industries in the past half century. ${ }^{1,2}$
Having experienced these challenges first hand, we have previously proposed how they can be translated into opportunities to increase the scientific contributions of other nations. ${ }^{3}$ For many years, our commitment to promote this change in paradigm has focused on education through the development of initiatives aimed to promote medical research in developing countries. A few years after introducing a novel program on global clinical research training using innovative web tools, ${ }^{{ }^{*}}$ we decided to enhance our offering and go beyond the books and lectures by creating the Principles and Practice of Clinical Research Fellow Practice (formerly known as the Latin American Initiative). Through this program, we coupled our theoretical training with hands-on research experience by giving medical scientists from developing nations the chance of working as research fellows in world-renowned laboratories. Our goal: to train the future investigators that will become regional and global leaders for international collaboration in clinical research and medical education. As our training program has grown steadily throughout the years, so has our class of fellows that have had the opportunity to join us in Boston. In only three years, more than forty young doctors from many parts of the world have become part of this ever-growing family of professionals committed to adding their contribution to the advancement of their field. After going through a laborious application process, which commonly starts every June, each February we welcome and assign fellows to either basic science, clinical, or translational research laboratories in Harvard Medical School-affiliated hospitals.

Thanks to the outstanding performance of past fellows, we have been able to increase, year after year, the number and variety of specialties offered. We are proud to be part of those changes that are taking place worldwide that will bring forward the scientific advancement of developing countries. By planting the seed through means of education and training, we feel certain that the drive force to scientific development will reverberate and expand globally.

${ }^{1}$ Jackson Memorial Hospital, Leonard M. Miller School of Medicine, Miami, FL

${ }^{2}$ Beth Israel Deaconess Medical Center, Harvard Medical School, Boston, MA.

${ }^{3}$ Spaulding Rehabilitation Hospital and Massachusetts General Hospital, Harvard Medical School, Boston, MA

* These authors contributed equally to this work. 


\section{Editorial}

We commend the editorial board of the International Journal of Medical Students on their noble initiative of providing the much needed resources to promote the scientific growth and contribution of doctors-in-training from around the world. We proudly share the same motivating force that looks for the development of well-rounded professionals committed to the progress of the medical sciences.

* Principles and Practice of Clinical Research. Collaborative and Distance Learning Program in Clinical Research. Department of Continuing Medical Education. Harvard Medical School. Boston, Massachusetts, United States. (www.clinicalresearchlearning.org).

\section{References}

1. Moloney A. Latin America faces hurdles in health research. Lancet 2009;374(9695):1053-4.

2. Clickman SW, McHutchison JG, Peterson ED, et al. Ethical and scientific implications of the globalization of clinical research. N Engl J Med 2009;360(8):816-23.

3. Coronel E, Halstead D, Fregni F. Clinical research in Latin America: obstacles and opportunities. Clinical Investigation 2011;1(7):911-3.

4. Carvas M, Imamura M, Hsing W, Dewey-Platt L, Fregni F. An innovative method of global clinical research training using collaborative learning with Web 2.0 tools. Med Teach 2010;32(3):270.

\section{Acknowledgements}

None.

Conflict of Interest Statement ct Funding

The Authors have no funding, financial relationships or conflicts of interest to disclose.

Cite as:

Coronel E, Anez-Bustillos L, Fregni F. Training Future Scientists - Enhancing Research Capabilities in Developing Nations. Int J Med Students. $2013 ; 1(2): 64-5$. 